\title{
Midiendo la estabilidad ministerial en los inicios del Estado argentino (1862-1898)*
}

\author{
Measuring Ministerial Stability in the Beginnings of the \\ Argentinean State (1862-1898)
Medindo a estabilidade ministerial no início do Estado argentino (1862-1898)
Juan Manuel Abal Medina** María Laura Eberhardt*** y Andrea Ariza****

\begin{abstract}
Resumen
Este artículo forma parte de una investigación más amplia que se propone relevar y analizar la composición y rotación de los gabinetes de ministros de los titulares del ejecutivo nacional argentino en el periodo 1862-1952. En este paper abordaremos específicamente el primer tramo de dicho periodo, entre 1862 y 1898, en el cual tanto la cantidad (cinco) como las áreas de los ministerios (del Interior, Relaciones Exteriores, Justicia, Culto e Instrucción Pública, Guerra y Marina, y Hacienda) estaban prefijadas por la Constitución nacional. El objetivo de este trabajo es por un lado descriptivo, y consiste en dar cuenta de: qué ministros fueron designados a nivel nacional en la Argentina, por qué presidentes, al frente de qué carteras y por cuánto tiempo. La fuente principal de información a utilizar serán los Libros de Ac-
\end{abstract}

Palabras clave: estabilidad del gabinete, gobierno nacional, ministerios, ministros.

Este artículo presenta resultados preliminares de una investigación llevada a cabo en el Proyecto UBACYT 20020150100147BA, "Redefiniendo los modelos de partido en el siglo XXI: más allá del Burocrático de Masas y más acá del Profesional Electoral”, radicado en la Universidad de Buenos Aires (Argentina). Los autores agradecen las valiosas críticas y comentarios de María Eugenia Coutinho y de los dos evaluadores anónimos que han permitido mejorar sustantivamente este trabajo.

* Doctor en Ciencias Políticas, Facultad Latinoamericana de Ciencias Sociales, México (FLACSO, México). Consejo Nacional de Investigaciones Científicas y Técnicas (CONICET). E-mail: jmanumedina@gmail.com

*** Doctora por la Facultad de Derecho, Área de Derecho Político, Universidad de Buenos Aires. Consejo Nacional de Investigaciones Científicas y Técnicas (CONICET). E-mail: laura_rafaela@yahoo.com.ar

Licenciada en Sociología, Universidad de Buenos Aires. Facultad de Ciencias Sociales, Universidad de Buenos Aires. E-mail: andrea.ariza93@gmail.com 
tas de Juramentos de los Miembros del Gobierno de la Nación Argentina, pertenecientes a la Escribanía General del Gobierno de la Nación. Por otro lado, se analizará la estabilidad/inestabilidad de los gabinetes, medidas a partir de una herramienta específica aquí propuesta: el Índice de Estabilidad de Gabinetes (IEG), que procura convertirse en un instrumento útil para futuros análisis sobre otros periodos y/o regímenes presidencialistas. Finalmente, formularemos hipótesis que intenten dar cuenta de las principales variaciones observadas bajo una perspectiva politológica que, a su vez, articule la consideración histórica de la época.

\section{ABSTRACT}

This article is part of a broader research study that aims to analyze the composition and rotation of the national cabinet in the period from 1862-1952. This paper specifically addresses the first part of that period, from 1862 to 1898 , in which both the quantity (five) and the areas of the ministries (Interior; Foreign Affairs; Justice, Religious Affairs, and Public Instruction; War and Navy; and Finance) were pre-established by the national Constitution. The objective of this paper is, on the one hand, descriptive and consists of giving an account of which national ministers were appointed in Argentina by which presidents, for which ministries, and for how long. At the same time, a first index proposal is formulated to comparatively analyze the degree of stability/ instability of the cabinets. The main source of information is the Record Books of Sworn National Government Members in Argentina, kept by the General Notary of the National Government. On the other hand, the stability/instability of the cabinets will be analyzed, measuring this using with a specific tool proposed here, the Cabinet Stability Index (IEG), which seeks to become a useful instrument for future analyses of other periods and/or presidential regimes. Finally, we will formulate hypotheses that attempt to account for the main variations observed, from a political perspective that, in turn, articulates the historical considerations of the time.

\section{RESUMO}

Este artigo faz parte de uma investigação mais ampla cujo objetivo é pesquisar e analisar a composição e rotação dos gabinetes de ministros dos titulares do executivo nacional argentino no período de 1862-1952. Neste trabalho trataremos especificamente da primeira parte desse período, entre 1862 e 1898, na qual tanto a quantidade (cinco) como as áreas dos ministérios (Interior, Relações Exteriores, Justiça, Culto e Instrução Pública, Guerra e
Keywords: cabinet stability, national government, ministries, ministers.

Palavras-chave: estabilidade do gabinete, governo nacional, ministérios, ministros. 
Marinha e Finanças) foram predeterminadas pela Constituição Nacional. O objetivo deste trabalho é, por um lado, descritivo e consiste em divulgar quais ministros foram nomeados em nível nacional na Argentina, por quais presidentes, à frente de quais pastas e por quanto tempo. A principal fonte de informação utilizada serão os Livros de Atas de Juramentos dos Membros do Governo da Nação Argentina, pertencentes ao Cartório Geral do Governo da Nação. Por outro lado, será analisada a estabilidade/ instabilidade dos gabinetes, medidas a partir de uma ferramenta específica aqui proposta: o Índice de Estabilidade de Gabinetes (IEG), que visa se tornar um instrumento útil para análises futuras de outros períodos e/ou regimes presidencialistas. Finalmente, formularemos hipóteses que tentem explicar as principais variações observadas sob uma perspectiva politológica que, por sua vez, articule a consideração histórica da época. 


\section{Introducción}

Este artículo forma parte de una investigación más amplia que se propone relevar y analizar la composición de los gabinetes de ministros de los titulares del Ejecutivo Nacional argentino desde 1862 hasta la actualidad. Esto es, desde el inicio del gobierno de Bartolomé Mitre (el primero en ejercer el cargo con el nombre oficial de Presidente de Argentina) hasta los inicios de la gestión de Alberto Fernández en 2020.

El recorte temporal del proyecto se divide en tres tramos. Un primer tramo, en el que se centra este artículo va de 1862 a 1898, en que tanto la cantidad (cinco) como los ramos de los ministerios (del Interior; Relaciones Exteriores; Justicia, Culto e Instrucción Pública; Guerra y Marina; y Hacienda) estaban determinados por la Constitución. El segundo tramo, que quedará para un futuro trabajo, iniciado en 1898 y finaliza en 1952, en que solo el número de ministerios (ocho), pero ya no sus áreas, estaban fijados por la Ley Fundamental; $\mathrm{y}$, finalmente, el tercero, desde esa fecha hasta nuestros días en el que el número de ministerios ascendió y se diversificaron sus áreas en virtud de la reforma de 1949 (derogada en 1957) y del Estatuto Fundamental de 1972, que eliminaron de la Constitución la determinación del número de ministerios y trasladaron a la ley correspondiente (propuesta por el ejecutivo) la potestad de definir su cantidad y sus áreas de competencia.

El primer objetivo de este trabajo es descriptivo y consiste en dar cuenta de qué ministros fueron designados, por cuáles presidentes, al frente de qué carteras y por cuánto tiempo. Para ello se llevará a cabo un estudio en profundidad por presidencia del modo en que se conformaron y modificaron los gabinetes nacionales en los sucesivos gobiernos - entre los años 1862 y 1898. Al final de la referencia de cada presidencia, se confeccionará un cuadro resumen para hacer evidente, a simple vista, la duración de cada ministro en su cargo y los cambios de titulares de cartera registrados bajo cada titular del ejecutivo. La estrategia de análisis incluirá la triangulación de técnicas y datos, tanto cualitativos como cuantitativos. La fuente principal de información son los Libros de Actas de Juramentos de los Miembros del Gobierno de la Nación Argentina pertenecientes a la Escribanía 
General del Gobierno de la Nación ${ }^{5}$, la que será acompañada con bibliografía académica multidisciplinaria sobre la época.

Esta primera aproximación descriptiva, tanto cuantitativa como cualitativa respecto de la conformación de los gabinetes en las primeras presidencias del país, aportará una base de datos completa y sistemática sobre la cual se podrá luego extender el análisis a los siguientes periodos, así como avanzar en estudios específicos respecto de, por ejemplo, la extracción social y la trayectoria política de los ministros nacionales en cada mandato, la existencia de patrones de conducta similares o diferentes en cuanto a la composición y permanencia de los ministros y los ministerios entre gobiernos democráticos y gobiernos de facto; y la cantidad y ramas de los ministerios y sus variaciones durante cada periodo, entre muchos otros hasta el momento poco explorados en todos los tramos de la historia argentina, esto es, desde los comienzos del Estado Nación hasta la actualidad.

Un segundo aporte concreto de este trabajo consiste en adentrarnos en el aspecto más sustantivo: el estudio del nivel de estabilidad/ inestabilidad de los gabinetes. Para ello, presentamos un índice, el IEG, destinado a medir, con vista a futuros análisis de caso y comparados, el grado de permanencia o rotación registrado en la conformación de los gabinetes ministeriales por cada presidente. Este dato deberá ser luego interpretado en relación con el tipo de régimen del que se trate (democrático o no democrático), del contexto político, social y económico (estabilidad, crecimiento o crisis), de la extracción ideológico-partidaria del presidente, de las trayectorias de los ministros, etc.

Finalmente, a la luz de los datos arrojados por el índice, formularemos algunas hipótesis orientadas a dar cuenta de las principales variaciones detectadas en cada gobierno, tomando principalmente en cuenta el contexto histórico en el que se desarrollaron, cuando las guerras civiles, la extensión de la frontera frente al indio, los enfrentamientos por cuestiones limítrofes y las crisis mundiales se convierten en factores insoslayables en este análisis.

Parte de la información contenida en estas actas fue utilizada y publicada por uno de los autores de este articulo en el análisis de los gobiernos y gobernantes argentinos (Abal Medina, 2019). 


\section{Estado de la cuestión}

En comparación con la riqueza y amplitud relevada en la investigación científica en el área de estudios presidenciales (Serrafero, 2011), el ámbito específico de sus gabinetes nacionales es un terreno menos explorado en la Argentina. Esta carencia se verifica tanto en producciones teóricas como en estudios empíricos. Como sostiene Gené (2007), “los estudios sobre los ministerios y sobre las elites gubernamentales aún no constituyen una tradición de investigación en nuestro país" (p. 15).

Sin embargo, en los últimos años se han dado a conocer valiosas producciones en esta área. En primer lugar, citamos el texto de Camerlo y Coutinho (2019) que analiza la afiliación partidaria de los ministros en el caso argentino. Previamente, Camerlo (2013) abordó los gabinetes de partido único en el mismo país, indagando las modalidades de selección de ministros en situaciones donde el soporte legislativo de coalición perdía relevancia. También, Heredia, Gené y Perelmiter (2012) impulsaron una investigación destinada a reconstruir la historia, las prerrogativas, la dinámica y los vínculos dentro y entre las carteras que conforman el Gabinete Nacional argentino desde 1976 en adelante.

Algunas publicaciones se abocaron al estudio del gabinete presidencial y su importancia para el régimen presidencialista. Valadés (2003) propone como meta el logro de un sistema presidencial más democrático a partir de la construcción de un gobierno de gabinete o "presidencialismo racionalizado". Por su parte, Carreras (2013) analiza el impacto de los presidentes outsiders en la composición del gabinete en Perú entre 1980 y 1995. Su hipótesis es que los gobernantes outsiders tienden a nombrar ministros técnicos e independientes. En esta línea, Dávila, Olivares Lavados y Avendaño (2013) se preguntan si existe una relación entre el tipo de ministerio (político, social, económico o mixto) y el tipo de educación de los ministros. En busca de la respuesta, observan los perfiles ministeriales en las cuatro administraciones de la Concertación de Partidos por la Democracia en Chile. Inácio (2013), por su lado, suma un trabajo enfocado en los gobiernos multipartidistas formados en Brasil (1995-2010), examina la elección de los ministros y estima las posibilidades de selección de los políticos profesionales vis-à-vis la selección de técnicos o políticos novatos en gabinetes multipartidistas. 
Asimismo, Chasquetti, Buquet y Cardarello (2013) analizan la formación y el cambio de gabinetes presidenciales en Uruguay (19852010). Por esa vía, detectan la existencia de un patrón de designación del gabinete cuyos atributos principales son: el establecimiento de un orden jerárquico de las carteras, la nominación de individuos con filiación partidaria y la influencia de los apoyos legislativos en la definición del elenco ministerial. A su vez, Martínez Gallardo (2012) realiza un trabajo comparativo a partir del estudio de 121 gabinetes en 12 países de América Latina entre 1980 y 2000 y observa que existe una amplia variación en la durabilidad de los gobiernos de coalición. Concluye que la disolución del gabinete es más probable cuando el presidente asigna menos valor a la construcción de coaliciones como estrategia de formulación de políticas y cuando los partidos encuentran un costo demasiado alto en participar en el gobierno. Por último, Camerlo y Martínez Gallardo (2018) indagan en la organización del poder ejecutivo y el funcionamiento de los gabinetes ministeriales en ocho democracias presidencialistas: EE.UU., Costa Rica, Uruguay, Chile, Brasil, Colombia, Perú y Ecuador.

Existe otra serie de trabajos que abordan la cuestión ministerial pero no lo hacen en forma directa, sino como uno más de los factores a considerar respecto del funcionamiento de la presidencia, junto con otros elementos, como: las coaliciones partidarias, los ciclos electorales, los liderazgos presidenciales. Para mencionar algunos ejemplos, Araujo Filho (2016) se preocupa por la fuerza personalista de los líderes políticos que llegan a la presidencia en América Latina en general y en Brasil en particular. El autor distingue el poder individual de los presidentes de la capacidad de implementar políticas públicas en Brasil a partir de la descripción de la burocracia ligada al gabinete en distintos gobiernos del siglo XX. Coutinho (2008) también incorpora la consideración de los gabinetes y ministros dentro del análisis más general de la organización de la presidencia en la Argentina. Finalmente, Amorim Neto (2002, 2006) avanza sobre estrategias presidenciales específicas, tales como las designaciones en los gabinetes ministeriales y sus consecuencias políticas.

En la Argentina también se ha estudiado la incorporación y desempeño de la figura del Jefe de Gabinete de Ministros a partir del pacto de Olivos celebrado entre el expresidente Alfonsín (Unión Cívica Radical) 
y el entonces presidente Menem (Partido Justicialista), y la concomitante reforma constitucional de 1994. Esta figura atrajo la atención de numerosos estudiosos de los regímenes políticos, en especial de los presidencialismos, por tratarse de una institución tan novedosa como heterodoxa, más cercana a los sistemas parlamentarios. Para citar solo algunos de ellos, mencionamos: Serrafero (1994, 1999b, 2003), Arismendi (1998), Cruz Barbosa (2010) y Coutinho (2019).

En lo que concierne al interés central de esta investigación, la cantidad y ramas de los ministerios existentes en cada presidencia, las modificaciones de ministros y ministerios registradas en las mismas y la medición del grado de estabilidad/inestabilidad de los gabinetes en los presidencialismos latinoamericanos, existen varias publicaciones académicas, aunque la mayoría de ellas inicia su análisis en el siglo XX.

Por ejemplo, Serrafero (2014) define la "inestabilidad ministerial" (p. 90) como una frecuencia de rotación de ministros por presidencia superior al promedio; la considera un indicador de la crisis institucional que envolvió a gran parte de los presidentes renunciantes en la Argentina. Por su parte, Ollier y Palumbo (2016) analizan la trayectoria de los gabinetes argentinos entre 1983 y 2015. Se preguntan sobre la formación de los gabinetes en el presidencialismo argentino y detectan la convergencia de causas fundamentales y causas próximas. Abocado a estudiar el mismo caso, Campos Ríos (2012) indagó la composición, la conformación y las variaciones del gabinete ministerial en la Argentina entre 1983 y 2007. Un trabajo más reciente del autor (Campos Ríos, 2019), extiende el estudio hasta alcanzar el inicio de la presidencia de Alberto Fernández —diciembre de 2019.

Respecto al estudio de los elencos políticos, Ferrari (2012) ofrece algunas reflexiones sobre su abordaje sociográfico, sus prácticas y sus autorrepresentaciones en la Argentina desde el arribo de la última dictadura militar hasta nuestros días. Por este camino, Aelo (2006) se aventura aún más atrás y observa el proceso de formación y crisis de la elite dirigente en el peronismo bonaerense de 1946 a 1951. En dicha línea de estudios sobre los orígenes y comportamientos de los liderazgos políticos, Heredia (2017) suma un significativo aporte en términos de sociología de las elites, a las que considera una vía de acceso a la comprensión y el control sobre los mecanismos de acumulación, dis- 
tribución y uso de la riqueza y el poder en un Estado. La producción de Donatello también se encuadra en esta temática de las elites, pero su mirada se posa no solo en el ámbito político (como en su estudio publicado con Levita ( Donatello \& Levita, 2017) sobre los diputados outsiders en los países del Mercosur entre 2003 y 2015), sino que se interesa además por las elites sociales, económicas y religiosas.

En cuanto a los estudios de gabinetes que incorporan el abordaje de la segunda mitad del siglo XIX en la Argentina, encontramos a Giorgi (2014a, 2014b), quien se enfoca en los llamados factores extrapolíticos de la carrera de los dirigentes y funcionarios públicos. Asimismo, observa las sociabilidades de los ministros nacionales durante el amplio periodo que va desde 1854 a 2011.

Existe además gran número de textos clásicos de historiadores, sociólogos y politólogos que explican la formación del Estado argentino y que dan cuenta de momentos de inestabilidad y/o debilidad institucional en términos de los enfrentamientos bélicos externos e internos. Estos análisis necesariamente incluyen una referencia explícita a la cuestión del origen y el desempeño de la dirigencia política, aunque esta última no constituya el eje central de los mismos. Uno de tales trabajos es el de Oszlak $(1982,2006)$, que articula una mirada multidisciplinar sobre el proceso de adquisición de los atributos de "estatidad", de construcción de la nación y de conformación de la sociedad argentina. Otra obra de referencia infaltable es la de Sábato (2005), quien, desde una mirada historicista, abarca la construcción de la república haciendo foco en los conceptos de pueblo y política. Finalmente, en esta enumeración no pueden faltar O’Donnell (1977) ni Halperin Donghi (1980), con sus respectivos análisis de los proyectos de construcción del Estado y la nación argentina.

El presente trabajo pretende contribuir a estos debates; específicamente tomando como punto de partida la presidencia de Mitre en 1862, se aviene a analizar la composición y cambios registrados en los gabinetes de cada titular del ejecutivo hasta 1898. Desde una mirada politológica, pretende calcular el índice de estabilidad ministerial en cada periodo y dar cuenta de sus resultados a la luz de la contextualización histórica de los hechos. Finalmente, busca aportar información fehaciente sobre las designaciones ministeriales, proveniente de los registros oficiales de las Actas de la Escribanía General del Gobierno 
de la Nación a fin de despejar dudas y errores suscitados sobre aquellos tiempos.

\section{Estabilidad e inestabilidad de los gabinetes ministeriales: El Índice de Estabilidad del Gabinete (IEG)}

Como se desprende del apartado precedente, el grado de estabilidad en los gabinetes ministeriales, si bien ha sido considerado como una de las dimensiones importantes del fenómeno en estudio, no ha despertado, hasta ahora, una firme atención analítica. Probablemente, una de las causas de tal insuficiencia sea que, a partir de las sucesivas reformas constitucionales y normativas registradas desde los comienzos del Estado argentino, la modificación en el número de ministerios y/o en la duración de los periodos presidenciales, así como la repetición de personas como titulares de una misma o de varias carteras, complejizó al extremo la obtención, interpretación y comparación de los datos empíricos.

Para avanzar en esta dirección, hemos construido una herramienta destinada a medir de un modo preciso el grado de estabilidad/inestabilidad de los gabinetes: el aquí llamado Índice de Estabilidad del Gabinete (IEG). Se trata de un indicador del grado de rotación de los ministros bajo el mandato de un mismo presidente.

Antes de pasar a explicar brevemente el modo en que se construye dicho índice, es importante definir qué entendemos por uno de sus principales términos, que es el de gestión ministerial. Con el mismo, queremos dar cuenta del mandato de una persona (ministro) en tanto titular de un ministerio determinado, cuya duración se extiende desde el momento de su incorporación, como tal en las actas, hasta que dicho cargo es ocupado por otro funcionario (según conste en el mismo registro).

Si igual persona, una vez que ha dejado el cargo en una cartera, es luego designada como titular del mismo ministerio al que dimitió o bajo algún otro de igual o diferente presidencia, inicia una nueva gestión ministerial. Si la misma persona continúa designada al frente de un mismo ministerio tras haber finalizado el correspondiente mandato presidencial (por golpe de Estado o por cumplimiento del periodo), inicia una nueva gestión ministerial bajo el/la nuevo/a presidente/a, 
contada desde el momento de su aparición en las Actas o, si ello no ocurriera, desde la aparición del nuevo primer mandatario.

Esto último ocurre igualmente en caso de salida anticipada de un presidente, cuando este es reemplazado para completar el periodo por quien corresponde según la línea sucesoria. En dicho caso, también se inicia una nueva gestión ministerial del ministro designado por el presidente saliente, contada a partir de la fecha de asunción del sucesor presidencial. Es decir, la gestión ministerial será siempre dentro del mandato del mismo titular del ejecutivo, y así formalmente diremos la gestión de A en el ministerio B durante el mandato de C.

Ahora bien, el mencionado Índice de Estabilidad del Gabinete se construye, en primer lugar, a partir de la Sumatoria de la cantidad total de Gestiones Ministeriales (SGM) registradas bajo un mismo gobernante. Esta sumatoria se divide luego por la cantidad de ministerios (carteras) establecidos en la normativa correspondiente: la Restricción Legal de Ministerios (RLM). El resultado (Y), que expresa en promedio la cantidad de ministros por cartera durante esos años, es luego dividido por el tiempo de duración del gobernante (T). Este último número se obtiene dividiendo la cantidad total de días que estuvo una misma persona como titular del ejecutivo por 365.25 (extensión de un año expresada en días).

De tal modo, se pretende controlar el efecto que pueda tener sobre el resultado final la diversa duración de los presidentes en el cargo. Cuanto mayor es el resultado arrojado por este índice, más inestable es el gabinete, esto es, una mayor cantidad de ministros circularon por los ministerios bajo el mandato de un presidente y, por tanto, mayor es el nivel de rotación de los titulares de sus carteras. En términos ilustrativos, podemos decir que si un presidente tuvo a las cinco mismas personas ocupando siempre las mismas cinco carteras habilitadas por la Constitución, la SGM es igual a la RLM, por lo tanto Y es igual a 1. Si ese presidente tuvo un mandato completo (seis años por aquel entonces), el IEG será de 0.166 periódico. Este número fija el valor mínimo de nuestro índice en estos años ${ }^{6}$.

\footnotetext{
$6 \quad$ El IEG está evidentemente vinculado conceptualmente a la duración del mandato presidencial. Es más "estable" un gabinete en el que todos sus miembros se mantienen por seis años que uno en el que lo hacen por un tiempo menor (por ejemplo, cuatro
} 


\section{Fórmula del Índice de Estabilidad del Gabinete (IEG)}

$$
\mathrm{IEG}=\mathrm{SGM} / \mathrm{RLM}=\mathrm{Y} / \mathrm{T}
$$

Finalmente tenemos que aclarar que, en su actual formulación, el IEG solo es aplicable a regímenes con una cantidad fija de carteras ministeriales, como lo fue la Argentina hasta la reforma constitucional de 1949. Para su aplicación a regímenes con un número variable de ministerios, dicho índice requerirá de modificaciones.

\section{Haciendo un poco de historia: Encuadre de los procesos políticos del periodo}

El periodo 1862-1898 fue el inicio de una nueva época. En 1861, el triunfo de las tropas porteñas en la batalla de Pavón y el posterior acuerdo firmado entre su líder, Bartolomé Mitre y el ex presidente de la Confederación Argentina, el caudillo entrerriano Justo José de Urquiza, abrió el camino para la reorganización política e institucional de la República Argentina. En 1862, la fórmula Mitre-Paz fue electa para iniciar el tercer periodo constitucional, contado desde la Ley Fundamental de 1853 (Sáenz Quesada, 2001).

La construcción del Estado nacional era un objetivo compartido por la dirigencia política de aquel entonces (Sábato, 2012), pero las características que este debía adquirir y los mecanismos para alcanzarlos fueron, en cambio, motivo de profundas y violentas disputas. El gobierno del liberal Mitre convivió con dos movimientos de impugnación al poder político central: los levantamientos federales de los caudillos en el interior y el autonomismo porteño liderado por Adolfo Alsina (Botana, 1977). A estas disputas internas, en 1865, se sumó la guerra de la Triple Alianza (Argentina, Uruguay y Brasil) contra el Paraguay.

Los enfrentamientos debilitaron a los federales (Bonaudo \& Sonzogni, 1999), pero también a los liberales mitristas. Pronto, grupos del tronco de Mitre, entre ellos Adolfo Alsina, formarían una constelación política más amplia a la que sumarían viejos federales del interior (Sá-

años). Por lo tanto, este número de 0.166 será el más bajo de toda la historia argentina, no solo de este primer periodo (1862-1898), y reflejará el mayor grado de estabilidad posible en un gabinete. Por el contrario, en el caso de que ese mismo presidente hubiera cambiado a todos sus ministros todos los días durante sus seis años, el IEG sería de 365.25, cifra que da cuenta del cambio diario de integrantes. 
bato, 2012). Estos impusieron la candidatura presidencial de Domingo Sarmiento y, en 1868, quebraron la continuidad de Mitre (Botana, 1977). Sarmiento "le imprimió a la gestión presidencial un sello reformista y centralizador distintivo" (Sábato, 2012, p. 177). En 1870, afrontó el fin de la guerra con Paraguay y neutralizó los alzamientos mitristas y federales en algunos territorios del interior. Próximo al fin de su mandato, designó como sucesor a Nicolás Avellaneda.

A partir de su cargo como ministro de Sarmiento, Avellaneda cosechó apoyos de las elites del interior. Su triunfo en 1874 suscitó enojos y resistencias en el sector mitrista. Convencido de que en la elección se había cometido fraude, Mitre se levantó en un intento revolucionario (Olivares, 2018), el que fue rápidamente contenido por un actor político consolidado en los últimos años: el Ejército Nacional. La disputa política entre autonomistas (de Alsina) y nacionalistas (de Mitre) atravesó su gobierno. Si bien hizo grandes esfuerzos para profundizar la integración de la economía en el mercado mundial, la larga y profunda crisis desatada en 1873 recién empezaría a revertirse en 1877. La búsqueda de nuevas tierras para ampliar la producción y el consecuente enfrentamiento con el indio adquirió gran centralidad, tanto bajo el ministerio de Alsina en Guerra y Marina como en manos del ministro sucesor Julio Argentino Roca. Finalmente, para cerrar el conflicto entre Alsina y Mitre, el presidente propuso una conciliación en 1877 e incorporó algunos mitristas a su gabinete. Los grupos dominantes del interior insistían en la necesidad de subordinar definitivamente a Buenos Aires para consolidar institucionalmente el país (Bonaudo \& Sonzogni, 1999).

Entretanto, Roca emergió como un actor central por su conquista de nuevas tierras y se impuso como candidato presidencial con el apoyo de Avellaneda y de Miguel Juárez Celman; este último, concuñado de Roca y recientemente electo gobernador de Córdoba. Ni bien celebradas las elecciones, el candidato opositor y gobernador de Buenos Aires, Carlos Tejedor, se levantó en armas en defensa de la capital de la provincia. Tras su derrota, la ciudad de Buenos Aires fue cedida como capital federal de la República. En octubre de ese año, 1880, Roca asumió como presidente (Sáenz Quesada, 2001).

El gobierno de Roca inauguró una etapa de hegemonía del Partido Autonomista Nacional (PAN), partido liberal-conservador creado en 
1874 por la unión de los partidos autonomista (de Alsina) y nacional (de Avellaneda), cuyos candidatos ganarían todas las elecciones hasta 1910, desplazando a la oposición. Roca concentró el poder estatal y gozó de un gran periodo de bonanza económica debido a la ampliación del territorio argentino, el crédito externo y el desarrollo de la administración pública nacional (Sábato, 2012). Los principales conflictos a los que se tuvo que enfrentar se encontraban dentro del PAN y giraron en torno a su sucesión. En 1885, Roca se inclinó por Miguel Juárez Celman como candidato oficial y aunó sus recursos con los del Estado para asegurar su triunfo.

En 1886, Juárez Celman asumió como presidente. Una vez en el cargo, tendió a concentrar el poder en su figura, y el llamado "juarismo" fue aumentando su fuerza, lo que derivó en la ruptura de relaciones con Roca. Además, hacia 1889, el periodo de bonanza económica se revirtió, desatándose una aguda recesión que dio lugar a la reactivación de la oposición y a sus constantes denuncias y protestas contra el régimen. En este contexto, el 26 de julio de 1890, la Unión Cívica (agrupación heterogénea presidida por Leandro Além -exintegrante del Partido Autonomista y ferviente opositor al régimen fraudulento instaurado por el PAN) perpetró la Revolución del Parque, forzando la renuncia de Juárez Celman.

Enseguida asumió su vicepresidente, Carlos Pellegrini, hombre de confianza de Roca, que enfrentó el desafío de restablecer el orden político y de revertir la crisis económica. Para ello, aplicó medidas de austeridad que le permitieron pilotear las dificultades y culminar su mandato (Sambuccetti de, 1971).

Luis Sáenz Peña, candidato presidencial también elegido por Roca, se impuso en las elecciones de 1892. Su gobierno fue débil y se desenvolvió en el marco de una gran inestabilidad debido a las disputas internas del PAN (Sábato, 2012). Esta inestabilidad se percibió en su gabinete que sufrió constantes cambios en el periodo. Además, en 1893 tuvo que afrontar revueltas periódicas suscitadas principalmente por integrantes de la Unión Cívica Radical (partido fundado en 1891 por Leandro Além tras la disolución de la Unión Cívica). Estos levantamientos terminaron por desgastarlo y, en enero de 1895, presentó su renuncia. 
Tras la renuncia del debilitado presidente, asumió la primera magistratura José Evaristo Uriburu, su vicepresidente, y se restableció la preeminencia de los hombres claves del régimen: Mitre, Roca y Pellegrini. Esta nueva relación de fuerzas, "permitirá un tránsito más sosegado hacia otra sucesión presidencial que culminará, finalmente, en manos del general Roca" (Serrafero, 1999a, p. 164). Durante su gestión se realizó el segundo censo nacional, se reunió la Convención Nacional Constituyente que modificó la Ley Fundamental y se enfrentó la cuestión limítrofe con Chile. En definitiva, Uriburu "tuvo una más tranquila administración y contó con el sostén de los notables del régimen" (Serrafero, 1999a, p. 165).

\section{Ministerios y ministros en la Constitución Nacional de 1853. La reforma de 1898}

\section{La Constitución de 1853}

Argentina es un país cuyo régimen de gobierno es democrático y su sistema político es presidencial. Su primera constitución nacional fue aprobada en el año 1853 y reformada en varias ocasiones, la última de ellas en 1994.

Respecto de los ministros y ministerios, aquella primera Ley Fundamental (Congreso General Constituyente, 2015) señalaba que solo la Cámara de Diputados ejerce el derecho de acusar ante el senado al Presidente y Vicepresidente de la Confederación y a sus ministros, a los miembros de ambas cámaras, a los de la Corte Suprema de Justicia y a los gobernadores de provincia por delitos de traición, concusión, malversación de fondos públicos, violación de la Constitución, u otros que merezcan pena infamante o de muerte (art. 41). Aquí la Constitución se estaría refiriendo al mecanismo de juicio político, herramienta extraordinaria de control horizontal entre poderes.

Por otro lado, agrega que tanto la Cámara de Diputados como la de senadores "puede hacer venir a su sala a los ministros del Poder Ejecutivo para recibir las explicaciones e informes que estime convenientes" (art. 60).

En lo que hace al gobierno, esta Constitución estipula que "el Poder Ejecutivo de la Nación será desempeñado por un ciudadano con el título de 'Presidente de la Confederación Argentina"' (art. 71), es decir, 
se trata de un órgano unipersonal y no colectivo, a diferencia de los parlamentarismos.

Dicha norma reconoce como una de las numerosas atribuciones del Presidente de la Confederación la de nombrar y remover a los ministros del despacho, los oficiales de sus secretarías, los agentes consulares y los demás empleados de la administración cuyo nombramiento no estuviera reglado de otra manera en su articulado (art. 83, inc.10). Se observa otra de las características de los sistemas presidenciales, que se refiere a la total potestad de los presidentes para elegir y destituir a su gabinete.

Específicamente, en lo que hace a los ministros del ejecutivo, la Constitución de 1853 dedica para su regulación todo el Capítulo IV de la Parte Segunda, Título Primero, Sección Segunda. Para comenzar, el artículo 84 establece cinco ministros secretarios, a quienes pone a cargo del despacho de los negocios de la confederación. Estos ministros deberán refrendar y legalizar los actos del presidente por medio de su firma. Agrega que, sin este aval, los actos presidenciales carecerán de eficacia. Los cinco ministros secretarios aquí mencionados son: del Interior, de Relaciones Exteriores, de Hacienda, de Justicia, Culto e Instrucción Pública, y de Guerra y Marina.

En cuanto a las obligaciones que les caben, el artículo 87 reza que, luego de la apertura de las sesiones del Congreso, los ministros del despacho deberán presentarle una memoria detallada del estado de la confederación en lo relativo a los negocios de sus respectivos departamentos. Cada ministro es responsable de los actos que legaliza y, solidariamente, de los que acuerda con sus colegas (art. 85). Estos no podrán, por sí solos, en ningún caso, tomar resoluciones sin previo mandato o consentimiento del Presidente de la Confederación, a excepción de lo concerniente al régimen económico y administrativo de sus respectivos departamentos (art. 86). A modo de retribución por sus servicios, gozarán de un sueldo establecido por ley que no podrá ser aumentado ni disminuido a favor o perjuicio de los que se hallen en ejercicio (art. 89).

En concordancia con lo antes referido, respecto de la separación e independencia de los poderes ejecutivo y legislativo en los regímenes presidenciales, el artículo 88 indica que los ministros "no pueden ser senadores ni diputados sin hacer dimisión de sus empleos de ministros", esto es, no pueden ejercer funciones ministeriales habiendo sido al mismo tiempo elegidos por el voto popular para integrar el parlamento. A lo 
sumo, se permite a los ministros concurrir a las sesiones del Congreso y tomar parte en sus debates, pero no pueden votar (art. 89).

\section{La reforma de 1898}

Tras las reformas de 1860 y de 1866, la del 15 de marzo de 1898 fue la primera modificación al texto constitucional que incorporó un cambio en el número de ministerios del poder ejecutivo. La necesidad de acrecentar la estructura del Estado fue resultado de los requerimientos propios del desarrollo económico y social evidenciados a fines del siglo XIX.

El nuevo artículo 87 quedó redactado por la Convención Nacional de 1897 del siguiente modo:

Ocho ministros secretarios tendrán a su cargo el despacho de los negocios de la Nación y refrendarán y legalizarán los actos del Presidente por medio de su firma, sin cuyo requisito carecen de eficacia. Una ley especial deslindará los ramos del respectivo despacho de los ministros (Convención Nacional, 2015, p. 179).

En esta versión ya no se estipulan los nombres o materias de cada ministerio, sino que dicha facultad queda ahora en manos del Congreso, las que se expedirán a través de la formulación de la ley correspondiente.

\section{Metodología/desarrollo: El tramo 1862-1898}

Siguiendo lo estipulado por la Constitución Nacional Argentina de 1853, desde la presidencia de Bartolomé Mitre (1862-1868) hasta la presidencia de José Evaristo Uriburu (1892-1898), el gabinete estaba compuesto por cinco departamentos de estados o ministerios: del Interior, de Relaciones Exteriores, de Justicia, Culto e Instrucción Pública, de Guerra y Marina, y de Hacienda.

En este primer tramo, hubo 25 ministros del Interior; 25 ministros de Relaciones Exteriores; 25 ministros de Justicia, Culto e Instrucción Pública; 19 ministros de Guerra y Marina; y 28 ministros de Hacienda. Cabe destacar que, a lo largo de todo este periodo, hubo ciertos nombres que ocuparon varias veces el mismo ministerio o que formaron parte del gabinete de distintos presidentes. Por ejemplo, Santiago Cortínez, quien fue ministro de Hacienda en la presidencia de Domingo Faustino Sarmiento (1868-1874), en la Nicolás Avellaneda (1874-1880) y en la de de Julio Argentino Roca (1880-1886). 


\section{Composición de los gabinetes por periodo presidencial}

\section{Bartolomé Mitre (1862-1868)}

Durante la presidencia de Bartolomé Mitre (1862-1868), el gabinete tuvo 10 ministros y 12 gestiones ministeriales en los seis años que duró el gobierno, y hubo siete cambios de gabinete. El Ministerio del Interior tuvo un solo ocupante por la totalidad del mandato. En Relaciones Exteriores y en Culto, Justicia e Instrucción Pública, hubo un cambio breve de ministros. No obstante, rápidamente retornaron a su antiguo cargo los dos ministros iniciales. Por su parte, en el departamento de Guerra y Marina, el cargo de ministro fue ocupado en casi todo el periodo por la misma persona, siendo solo reemplazado en los últimos meses. Finalmente, el departamento de Hacienda registró el mayor número de cambios de nombres: tres personas ocuparon el cargo de ministro a lo largo del periodo.

Tabla 1

Ministros durante la presidencia de Bartolomé Mitre (1862-1868)

\begin{tabular}{lll}
\hline \multicolumn{1}{c}{$\begin{array}{c}\text { Presidencia de } \\
\text { Bartolomé Mitre }\end{array}$} & \multicolumn{1}{c}{ Ministro } & \multicolumn{1}{c}{ Período } \\
\hline Del Interior & Guillermo Rawson & $15 / 10 / 1862$ a $12 / 10 / 1868$ \\
\hline Relaciones Exteriores & Rufino de Elizalde & $15 / 10 / 1862$ a $07 / 09 / 1867$ \\
\cline { 2 - 3 } & Marcelino Ugarte & $07 / 09 / 1867$ a 27/01/1868 \\
\cline { 2 - 3 } & Rufino de Elizalde & $27 / 01 / 1868$ a $12 / 10 / 1868$ \\
\hline Justicia, Culto e & Eduardo Costa & $15 / 10 / 1862$ a 07/09/1867 \\
\cline { 2 - 3 } Instrucción Pública & José Uriburu & $07 / 09 / 1867$ a $27 / 01 / 1868$ \\
\cline { 2 - 3 } & Eduardo Costa & $27 / 01 / 1868$ a $12 / 10 / 1868$ \\
\hline Guerra y Marina & Juan Andrés Gelly y Obes & $15 / 10 / 1862$ a 31/01/1868 \\
\cline { 2 - 3 } & Wenceslao Paunero & $31 / 01 / 1868$ a $12 / 10 / 1868$ \\
\hline Hacienda & Dalmacio Vélez Sarsfield & $16 / 10 / 1862$ a 02/03/1864 \\
\cline { 2 - 3 } & Lucas González & $02 / 03 / 1864$ a 27/01/1868 \\
\cline { 2 - 3 } & Cristóbal Aguirre & $27 / 01 / 1868$ a 12/10/1868 \\
\hline
\end{tabular}

Fuente: Elaboración propia en base a los Libros de Actas de Juramentos de los Miembros del Gobierno de la Nación Argentina.

De esta manera, con 12 gestiones ministeriales a lo largo de los seis años de gobierno, nuestro índice alcanza un valor de 0.40 . Parte de esta cifra, que incluye el retorno de ministros a su cartera inicial luego de una breve salida, puede explicarse en virtud del momento en el que el 
presidente Mitre delegó en su vicepresidente, Marcos Paz, la conducción del poder ejecutivo para comandar el ejército de la Triple Alianza (Brasil, Uruguay y Argentina) en la llamada "guerra del Paraguay" (Sáenz Quesada, 2001, p. 362). En sus seis meses de gobierno, el presidente interino reemplazó a los titulares de Relaciones Exteriores y de Justicia, Culto e Instrucción Pública. No obstante, tras su muerte y el obligado regreso de Mitre a la presidencia, retornaron a sus antiguos cargos los ministros iniciales.

\section{Domingo Faustino Sarmiento (1868-1874)}

Bajo la presidencia de Domingo Faustino Sarmiento (1868-1874) hubo un total de 11 ministros y en cuatro de los cinco departamentos de estado se registraron cambios de nombres. El ministro de Guerra y Marina fue el único miembro del gabinete que acompañó a Sarmiento durante todo su mandato. El primer departamento que cambió de titular (pero lo hizo solo una vez) fue el de Relaciones Exteriores. A los pocos meses, el departamento de Hacienda sufrió la primera de sus tres modificaciones. El departamento del Interior y el de Justicia, Culto e Instrucción Pública afrontaron una única modificación cada uno.

Tabla 2

Ministros durante la presidencia de Domingo Faustino Sarmiento (1868-1874)

\begin{tabular}{lll}
\hline \multicolumn{1}{c}{\begin{tabular}{c} 
Presidencia de \\
Domingo Faustino \\
\multicolumn{1}{c}{ Sarmiento }
\end{tabular}} & \multicolumn{1}{c}{ Ministro } & \multicolumn{1}{c}{ Período } \\
\hline Del Interior & Dalmacio Vélez Sarsfield & $12 / 10 / 1868$ a 27/06/1872 \\
\cline { 2 - 3 } $\begin{array}{l}\text { Relaciones } \\
\text { Exteriores }\end{array}$ & Uladislao Frías & $27 / 06 / 1872$ a 12/10/1874 \\
\cline { 2 - 3 } Justicia, Culto e & Carlos Tejedor & $12 / 10 / 1868$ a 18/08/1870 \\
Instrucción Pública & Nicolás Avellaneda & $12 / 10 / 1868$ a 24/11/1873 \\
\cline { 2 - 3 } & Juan Crisóstomo Albarracín & $24 / 11 / 1873$ a $12 / 10 / 1874$ \\
\hline Guerra y Marina & Martín de Gainza & $12 / 10 / 1868$ a 12/10/1874 \\
\hline Hacienda & Benjamín Gorostiaga & $12 / 10 / 1868$ a 14/10/1870 \\
\cline { 2 - 3 } & Cristóbal Aguirre & $14 / 10 / 1870$ a $11 / 02 / 1871$ \\
\cline { 2 - 3 } & Luís Lorenzo Domínguez & $11 / 02 / 1871$ a 23/02/1874 \\
\cline { 2 - 3 } & Santiago Cortinez & $23 / 02 / 1874$ a $12 / 10 / 1874$ \\
\hline
\end{tabular}

Fuente: Elaboración propia en base a los Libros de Actas de Juramentos de los Miembros del Gobierno de la Nación Argentina. 
En este periodo presidencial hubo once gestiones ministeriales, con lo que el valor del IGM es de 0.37. La mayor rotación se observa en el Ministerio de Hacienda. Los gastos extraordinarios requeridos tanto por la guerra con el Paraguay como para imponer en el interior del país el orden presidencialista (la guerra civil en Entre Ríos, el levantamiento de López Jordán en Santa Fe, las intervenciones a las provincias, las últimas conmociones montoneras del interior, las movilizaciones de la Guardia Nacional y los movimientos de tropas al mando de Arredondo y de Roca) ocasionaron desbalances en las cuentas públicas (Vedoya, 1979). Asimismo, el brote de fiebre amarilla a comienzos de 1871 azotó la ciudad de Buenos Aires y provocó graves pérdidas económicas en todo el país. La situación económica estuvo lejos de ser previsible o estable. Por otra parte, el fin de la guerra con el Paraguay en 1870 abrió el canal de negociación de los aliados con el país vencido. En ese marco, Carlos Tejedor asumió como nuevo ministro de Relaciones Exteriores. Su designación representó un cambio de táctica, pasando de una postura de reconciliación a otra más confrontativa (Sábato, 2012).

\section{Nicolás Avellaneda (1874-1880)}

Bajo el mando de Nicolás Avellaneda (1874-1880), los cambios de gabinete se produjeron en los cinco departamentos de estado. El departamento de Guerra y Marina fue el que menos modificaciones sufrió, ya que solo hubo dos cambios. En el departamento de Justicia, Culto e Instrucción Pública existieron tres modificaciones y en los departamentos del Interior, de Relaciones Exteriores, y de Hacienda, se registraron cuatro cambios de nombres.

En este periodo hubo, por tanto, 20 ministros y 22 nombramientos en total. El mismo ministro ocupó el Ministerio de Hacienda en dos oportunidades. Otras tres personas fueron también ministros de Hacienda bajo la presidencia de Avellaneda. Un nuevo funcionario fue primero ministro de Hacienda y luego de Relaciones Exteriores. El departamento del Interior y el de Relaciones Exteriores fueron ocupados por cinco titulares cada uno. El departamento de Justicia, Culto e Instrucción pública tuvo cuatro ministros, en tanto Guerra y Marina sumó tres designaciones. 
Tabla 3

Ministros durante la presidencia de Nicolás Avellaneda (1874-1880)

\begin{tabular}{|c|c|c|}
\hline $\begin{array}{c}\text { Presidencia de } \\
\text { Nicolás Avellaneda }\end{array}$ & Ministro & Período \\
\hline \multirow[t]{5}{*}{ Del Interior } & Simón de Iriondo & $12 / 10 / 1874$ a $08 / 05 / 1878$ \\
\hline & Saturnino Laspiur & 08/05/1878 a $25 / 08 / 1879$ \\
\hline & Héctor Álvarez & $25 / 08 / 1879$ a $01 / 09 / 1879$ \\
\hline & Domingo F. Sarmiento & $01 / 09 / 1879$ a $09 / 10 / 1879$ \\
\hline & Benjamín Zorrilla & $09 / 10 / 1879$ a $13 / 10 / 1880$ \\
\hline \multirow[t]{5}{*}{ Relaciones Exteriores } & Pedro Pardo & $12 / 10 / 1874$ a $03 / 08 / 1875$ \\
\hline & Bernardo de Irigoyen & 03/08/1875 a $03 / 10 / 1877$ \\
\hline & Rufino de Elizalde & 03/10/1877 a 09/05/1878 \\
\hline & Manuel Montes de Oca & 09/05/1878 a $09 / 10 / 1879$ \\
\hline & Lucas González & $09 / 10 / 1879$ a $13 / 10 / 1880$ \\
\hline \multirow{4}{*}{$\begin{array}{l}\text { Justicia, Culto e } \\
\text { Instrucción Pública }\end{array}$} & Onesimo Leguizamón & $13 / 10 / 1874$ a $04 / 10 / 1877$ \\
\hline & José María Gutiérrez & $04 / 10 / 1877$ a $09 / 05 / 1878$ \\
\hline & Bonifacio Lastra & 09/05/1878 a $10 / 10 / 1879$ \\
\hline & Miguel Goyena & 10/10/1879 a13/10/1880 \\
\hline \multirow[t]{3}{*}{ Guerra y Marina } & Adolfo Alsina & $12 / 10 / 1874$ a $22 / 04 / 1878$ \\
\hline & Julio Argentino Roca & $22 / 04 / 1878$ a $09 / 10 / 1879$ \\
\hline & Carlos Pellegrini & 09/10/1879 a 13/10/1880 \\
\hline \multirow[t]{5}{*}{ Hacienda } & Santiago Cortinez & $12 / 10 / 1874$ a $02 / 10 / 1875$ \\
\hline & Lucas González & $02 / 10 / 1875$ a $22 / 05 / 1876$ \\
\hline & Norberto de la Riestra & $22 / 05 / 1876$ a $31 / 08 / 1876$ \\
\hline & Victorino de la Plaza & $31 / 08 / 1876$ a $08 / 05 / 1880$ \\
\hline & Santiago Cortinez & $08 / 05 / 1880$ a $13 / 10 / 1880$ \\
\hline
\end{tabular}

Fuente: Elaboración propia en base a los Libros de Actas de Juramentos de los Miembros del Gobierno de la Nación Argentina.

En este periodo, con 22 gestiones ministeriales el IEG se eleva a 0.73 , prácticamente duplicando el valor de los dos mandatos presidenciales anteriores. Esto podría ser explicado por el intento de conciliación del presidente Avellaneda con la facción de Mitre, tras haberlo derrotado en las elecciones presidenciales correspondientes, y en el marco de una crisis económica que redujo los recursos estatales.

Recordemos que, en ocasión de la sucesión de Sarmiento, "los colegios electorales de todo el país favorecieron a Avellaneda, pero Mitre y el partido nacionalista no aceptaron el veredicto de las ur- 
nas, ciertamente dudoso, y se alzaron en armas como protesta por la distorsión del voto popular" (Sáenz Quesada, 2001, p. 376). Si bien la rebelión mitrista fue rápidamente derrotada, para evitar males mayores los rebeldes fueron amnistiados y el presidente Avellaneda se empeñó en "despejar el panorama político mediante la conciliación de los partidos autonomista y nacionalista". Por tanto, "a mediados de 1877 Avellaneda se entrevistó con Mitre y convinieron en incorporar a dos mitristas prominentes en el gabinete" (p. 383): Rufino de Elizalde y José María Gutiérrez, el que más tarde fue reemplazado por Bonifacio Lastra. El fracaso de la política de conciliación y la negociación de las candidaturas en 1879 produjeron nuevos cambios en el gabinete, entre ellos: el alejamiento de Lastra, Laspiur, Montes de Oca y Roca.

En cuanto al primer ministro de Guerra y Marina, Adolfo Alsina, desde 1874 tuvo a su cargo la difícil tarea de aplicar la política de frontera, que implicaba la conquista definitiva del desierto. Pocos años después, en diciembre de 1877 y antes de cumplir 50 años, Alsina murió "exhausto por el esfuerzo titánico que implicaba la inspección de la línea fronteriza, siempre a caballo" (Sáenz Quesada, 2001, p. 382).

Finalmente, la inestabilidad en la cartera de Hacienda estuvo influenciada por la crisis a la que se enfrentó el país a partir de 1873 debido a una restricción en el mercado de capitales. Esta crisis, originada en Austria, afectó a los mercados de Europa y Estados Unidos e impactó directamente en la Argentina hasta 1877 (Sábato, 2012).

\section{Julio Argentino Roca (1880-1886)}

Julio Argentino Roca (1880-1886) tomó juramento a 13 ministros: tres ministros en los departamentos del Interior, de Relaciones Exteriores y de Hacienda; y dos ministros en los departamentos de Culto, Justicia e Instrucción Pública, y de Guerra y Marina. Todos los departamentos de Estado sufrieron cambios de conducción durante el gobierno de Roca. 
Tabla 4

Ministros durante la presidencia de Julio Argentino Roca (1880-1886)

\begin{tabular}{|c|c|c|}
\hline $\begin{array}{l}\text { Presidencia de Julio } \\
\text { Argentino Roca }\end{array}$ & Ministro & Período \\
\hline \multirow[t]{3}{*}{ Del Interior } & Antonio del Viso & $13 / 10 / 1880$ a $09 / 06 / 1885$ \\
\hline & Benjamín Paz & 09/06/1885 a 12/04/1886 \\
\hline & Isaac Olavarría & $12 / 04 / 1886$ a $13 / 10 / 1886$ \\
\hline \multirow[t]{3}{*}{ Relaciones Exteriores } & Bernardo de Irigoyen & $13 / 10 / 1880$ a $14 / 02 / 1882$ \\
\hline & Victorino de la Plaza & $14 / 02 / 1882$ a $25 / 10 / 1883$ \\
\hline & Francisco Ortiz & $25 / 10 / 1883$ a $13 / 10 / 1886$ \\
\hline \multirow{2}{*}{$\begin{array}{l}\text { Justicia, Culto e } \\
\text { Instrucción Pública }\end{array}$} & Manuel Demetrio Pizarro & $13 / 10 / 1880$ a $14 / 02 / 1882$ \\
\hline & Eduardo Wilde & $14 / 02 / 1882$ a $13 / 10 / 1886$ \\
\hline \multirow[t]{2}{*}{ Guerra y Marina } & Benjamín Victorica & $13 / 10 / 1880$ a $28 / 09 / 1885$ \\
\hline & Carlos Pellegrini & 28/09/1885a 13/10/1886 \\
\hline \multirow[t]{3}{*}{ Hacienda } & Santiago Cortínez & $18 / 10 / 1880$ a $09 / 05 / 1881$ \\
\hline & Juan José Romero & 09/05/1881 a 10/03/1885 \\
\hline & Wenceslao Pacheco & $10 / 03 / 1885$ a $13 / 10 / 1886$ \\
\hline
\end{tabular}

Fuente: Elaboración propia en base a los Libros de Actas de Juramentos de los Miembros del Gobierno de la Nación Argentina.

Con 13 gestiones ministeriales, la estabilidad del gabinete de Roca aumenta en comparación con su antecesor y, con un valor del IEG de 0.43 , se asemeja al de las dos primeras presidencias del país. Bajo su mandato se avanzó en la tarea de crear una Argentina moderna: se prohibió la organización de milicias provinciales, se declaró a la ciudad de Buenos Aires Capital Federal de la República y se modernizó su puerto; se creó el Consejo Nacional de Educación, se aprobó la Ley No 1420 de educación común, las rentas nacionales aumentaron en gran medida, los ferrocarriles se extendieron al igual que la infraestructura urbana y portuaria, se organizó la justicia, se construyeron grandes edificios, se firmaron acuerdos con otros países y se nacionalizó la Universidad de Buenos Aires. En síntesis: "el país hizo progresos sorprendentes durante la primera presidencia de Roca" (Gandía de, 1979, p. 40). Si bien el presidente tuvo que resolver disputas limítrofes con Chile, enfrentar la oposición de algunos sectores clericales y completar la expansión de la frontera sur con el indio, este escenario de modernización y progreso constituyó un clima muy favorable a la estabilidad de su gobierno. 


\section{Miguel Juárez Celman (1886-1890)}

En el tiempo que duró el gobierno de Miguel Juárez Celman (18861890) hubo un total de 17 gestiones ministeriales. El departamento de Hacienda tuvo cinco nombramientos a lo largo del periodo. Uno de sus ministros asumió dos veces, ya que en el medio fue designado ministro del Interior; otro caso de rotación interna fue el de un ministro de Relaciones Exteriores, que luego fue trasladado al ministerio del Interior. En esta última cartera hubo cuatro nombramientos, mientras que en Relaciones Exteriores se produjeron tres designaciones. El departamento de Justicia, Culto e Instrucción Pública también fue dirigido por tres personas. Finalmente, Guerra y Marina estuvo liderado por dos funcionarios diferentes.

Tabla 5

Ministros durante la presidencia de Miguel Juárez Celman (1886-1890)

\begin{tabular}{|c|c|c|}
\hline $\begin{array}{l}\text { Presidencia de Miguel } \\
\text { Juárez Celman }\end{array}$ & Ministro & Período \\
\hline \multirow[t]{4}{*}{ Del Interior } & Eduardo Wilde & 13/10/1886 a 01/03/1889 \\
\hline & Wenceslao Pacheco & 01/03/1889 a 28/08/1889 \\
\hline & Norberto Quirno Costa & $28 / 08 / 1889$ a $18 / 04 / 1890$ \\
\hline & Salustiano Zavalía & $18 / 04 / 1890$ a $07 / 08 / 1890$ \\
\hline \multirow[t]{3}{*}{ Relaciones Exteriores } & Norberto Quirno Costa & $13 / 10 / 1886$ a $28 / 08 / 1889$ \\
\hline & Estanislao Zeballos & $28 / 08 / 1889$ a $30 / 06 / 1890$ \\
\hline & Roque Sáenz Peña & $30 / 06 / 1890$ a $07 / 08 / 1890$ \\
\hline \multirow{3}{*}{$\begin{array}{l}\text { Justicia, Culto e } \\
\text { Instrucción Pública }\end{array}$} & Filemón Posse & $13 / 10 / 1886$ a $18 / 04 / 1890$ \\
\hline & Amancio Alcorta & $18 / 04 / 1890$ a $09 / 06 / 1890$ \\
\hline & José Mariano Astigueta & 09/06/1890 a $07 / 08 / 1890$ \\
\hline \multirow[t]{2}{*}{ Guerra y Marina } & Eduardo Racedo & $13 / 10 / 1886$ a $18 / 04 / 1890$ \\
\hline & Nicolás Levalle & $18 / 04 / 1890$ a $07 / 08 / 1890$ \\
\hline \multirow[t]{5}{*}{ Hacienda } & Wenceslao Pacheco & $13 / 10 / 1886$ a $01 / 03 / 1889$ \\
\hline & Rufino Varela & 01/03/1889 a 28/08/1889 \\
\hline & Wenceslao Pacheco & $28 / 08 / 1889$ a $18 / 04 / 1890$ \\
\hline & Francisco Uriburu & $18 / 04 / 1890$ a $09 / 06 / 1890$ \\
\hline & Juan Agustín García & 09/06/1890 a $07 / 08 / 1890$ \\
\hline
\end{tabular}

Fuente: Elaboración propia en base a los Libros de Actas de Juramentos de los Miembros del Gobierno de la Nación Argentina. 
Aunque puede argumentarse que el número de gestiones ministeriales, 17, no parece muy discordante con las presidencias anteriores, es preciso hacer notar que las mismas se dieron en menos de cuatro años, ya que Juárez Celman debió renunciar tras la llamada Revolución del Parque liderada por Além en 1890. Con su salida anticipada del cargo, el valor de su índice de inestabilidad del gabinete se incrementa, alcanzando el número 0.89 , el más alto hasta ahora.

En términos históricos, no hay que olvidar que Juárez Celman llegó a la presidencia con el apoyo de Roca y de sus allegados. La alianza se selló con la designación de los roquistas Eduardo Wilde y Wenceslao Pacheco al frente de los ministerios del Interior y de Hacienda respectivamente (Sábato, 2012). En 1889, Wilde renuncia y en su lugar asume Pacheco. Una vez en el poder, el presidente asumió la jefatura del PAN, convirtiéndose en su jefe único (el llamado "unicato"). Este afán centralizador y su estilo autoritario de gobierno provocaron el distanciamiento de Roca, que derivó en el alejamiento de Pacheco de su cartera. A partir de entonces comenzó un proceso de reordenamientos del gabinete. Por otro lado, su deficiente gestión económica y los efectos de la recesión alimentaron la crisis y alentaron la movilización de la oposición.

\section{Carlos Pellegrini (1890-1892)}

Durante los dos años en los que Carlos Pellegrini se desempeñó como presidente (1890-1892), se contabilizaron 10 ministros. Al frente del Interior hubo dos titulares, al igual que en Hacienda y en Relaciones Exteriores. Justicia, Culto e Instrucción Pública tuvo tres ministros. El único ministerio que no registró cambios en este breve periodo fue el de Guerra y Marina. 
Tabla 6

Ministros durante la presidencia de Carlos Pellegrini (1890-1892)

\begin{tabular}{lll}
\hline \multicolumn{1}{c}{$\begin{array}{c}\text { Presidencia de } \\
\text { Carlos Pellegrini }\end{array}$} & \multicolumn{1}{c}{ Ministro } & \multicolumn{1}{c}{ Período } \\
\hline Del Interior & Julio Argentino Roca & $07 / 08 / 1890$ a 02/05/1891 \\
\cline { 2 - 3 } & José Vicente Zapata & $02 / 05 / 1891$ a 13/10/1892 \\
\hline Relaciones Exteriores & Eduardo Costa & $07 / 08 / 1890$ a 24/10/1891 \\
\cline { 2 - 3 } & Estanislao Zeballos & $24 / 10 / 1891$ a 13/10/1892 \\
\hline Justicia, Culto e & José María Gutiérrez & $07 / 08 / 1890$ a 29/10/1890 \\
\cline { 2 - 3 } Instrucción Pública & Juan Carballido & $29 / 10 / 1890$ a 24/10/1891 \\
\cline { 2 - 3 } & Juan Balestra & $24 / 10 / 1891$ a 13/10/1892 \\
\hline Guerra y Marina & Nicolás Levalle & $07 / 08 / 1890$ a 13/10/1892 \\
\hline Hacienda & Vicente Fidel López & $07 / 08 / 1890$ a 08/06/1892 \\
\cline { 2 - 3 } & Emilio Hansen & $08 / 06 / 1892$ a 13/10/1892 \\
\hline
\end{tabular}

Fuente: Elaboración propia en base a los Libros de Actas de Juramentos de los Miembros del Gobierno de la Nación Argentina.

Si bien la cantidad de gestiones ministeriales no fue muy elevada en esta etapa (10 en total), sus poco más de dos años de duración en el mando conducen a un IEG más bien alto, de 0.91, muy similar al de su compañero de fórmula, Juárez Celman. Probablemente, ello pueda deberse a las consecuencias del caótico proceso político que derivó en su propia asunción. Recordemos que Pellegrini llegó a la presidencia en un contexto de crisis política y económica, luego de la renuncia de su titular el 6 de agosto de 1890 como consecuencia de la presión ejercida en su contra por el Congreso tras el levantamiento de la Unión Cívica (UC).

El flamante presidente dejó traslucir "en el nuevo gabinete la corriente de fuerzas por donde había transitado el núcleo de la reacción institucional contra Juárez Celman: los moderados del Parque y los antijuaristas del PAN" (Serrafero, 1999a, p. 159), esto es, Roca, Eduardo Costa y José María Gutiérrez (dos mitristas) y Vicente Fidel López (ligado a la UC). De este modo, "se restablecía el equilibrio dentro de la clase dirigente y se reanudaban 'alianzas estratégicas"' (p. 159). Es decir, "Pellegrini salvaba la continuidad del régimen marcando la discontinuidad con el gobierno anterior" (p. 159). Aunque la institucionalidad fue preservada y el PAN se mantuvo en el poder, Pellegrini ejerció la presidencia en un contexto donde las bases concretas y simbólicas sobre las que el régimen conservador asentaba su funcionamiento se vieron considerablemente afectadas (Rojkind, 2012). 


\section{Luis Sáenz Peña (1892-1895)}

A lo largo de la presidencia de Luis Sáenz Peña (1892-1895) hubo un total de 27 nombramientos de ministros. Cuatro de estos funcionarios fueron designados en más de una oportunidad durante el periodo. En el departamento del Interior, se registraron seis ministros, al igual que en Relaciones Exteriores y en Justicia, Culto e Instrucción Pública. Guerra y Marina contó con cinco titulares, mientras que en Hacienda fueron designados cuatro ministros.

Tabla 7

Ministros durante la presidencia de Luis Sáenz Peña (1892-1895)

\begin{tabular}{|c|c|c|}
\hline $\begin{array}{l}\text { Presidencia de } \\
\text { Luís Sáenz Peña }\end{array}$ & Ministro & Período \\
\hline \multirow[t]{6}{*}{ Del Interior } & Manuel Quintana & $13 / 10 / 1892$ a $10 / 02 / 1893$ \\
\hline & Wenceslao Escalante & $10 / 02 / 1893$ a $27 / 06 / 1893$ \\
\hline & Miguel Cané & $27 / 06 / 1893$ a $06 / 07 / 1893$ \\
\hline & Lucio Vicente López & 06/07/1893 a 12/08/1893 \\
\hline & Manuel Quintana & 12/08/1893 a 10/01/1895 \\
\hline & Eduardo Costa & $10 / 01 / 1895 \mathrm{al} 23 / 01 / 1895$ \\
\hline \multirow[t]{6}{*}{ Relaciones Exteriores } & Tomas Anchorena & $13 / 10 / 1892$ a $08 / 06 / 1893$ \\
\hline & Miguel Cané & 08/06/1893 a 27/06/1893 \\
\hline & Norberto Quirno Costa & $27 / 06 / 1893$ a $6 / 07 / 1893$ \\
\hline & Valentín Virasoro & $6 / 07 / 1893$ a $16 / 12 / 1893$ \\
\hline & Eduardo Costa & 16/12/1893 a 10/01/1895 \\
\hline & Amancio Alcorta & $10 / 01 / 1895$ a $23 / 01 / 1895$ \\
\hline \multirow{6}{*}{$\begin{array}{l}\text { Justicia, Culto e } \\
\text { Instrucción Pública }\end{array}$} & Calixto de la Torre & 13/10/1892 a $24 / 03 / 1893$ \\
\hline & Amancio Alcorta & $24 / 03 / 1893$ a $27 / 06 / 1893$ \\
\hline & Francisco Lucio García & 27/06/1893 a 6/07/1893 \\
\hline & Enrique Quintana & 6/07/1893 a 12/08/1893 \\
\hline & Eduardo Costa & $12 / 08 / 1893$ a $14 / 04 / 1894$ \\
\hline & José Vicente Zapata & $14 / 04 / 1894$ a $23 / 01 / 1895$ \\
\hline \multirow[t]{5}{*}{ Guerra y Marina } & Benjamín Victorica & 13/10/1892 a 08/06/1893 \\
\hline & Joaquín Viejobueno & 08/06/1893 a 06/07/1893 \\
\hline & Aristóbulo del Valle & 06/07/1893 a 12/08/1893 \\
\hline & Luís María Campos & $12 / 08 / 1893$ a $10 / 12 / 1894$ \\
\hline & Eudoro Balsa & $10 / 12 / 1894$ a $23 / 01 / 1895$ \\
\hline \multirow[t]{4}{*}{ Hacienda } & Juan José Romero & 13/10/1892 a 08/06/1893 \\
\hline & Marco Avellaneda & 08/06/1893 a 06/07/1893 \\
\hline & Mariano Demaría & 06/07/1893 a 12/08/1893 \\
\hline & José Antonio Terry & 12/08/1893 a 23/01/1895 \\
\hline
\end{tabular}

Fuente: elaboración propia en base a los Libros de Actas de Juramentos de los Miembros del Gobierno de la Nación Argentina. 
En 1895, Luis Sáenz Peña renunció a la presidencia “fatigado por la lucha continua" (Sáenz Quesada, 2001, p. 418). Con 27 gestiones ministeriales en algo más de dos años de mandato, el periodo presidencial de este presidente es por lejos el más inestable hasta el momento. No solo tuvo el mayor número de designaciones, sino que lo combinó con uno de los gobiernos de menor duración. Esto se observa claramente en el valor del IEG, que llega a 2.37, más que duplicando a cualquiera de sus antecesores. La extremadamente alta inestabilidad ministerial da cuenta de las dificultades de gestión y de la debilidad política del presidente, la que finalmente derivó en su renuncia.

Brevemente, su candidatura había sido "producto de una jugada política del 'acuerdo' (bajo el sello de Roca) para evitar el ascenso de su hijo Roque". La presidencia de Sáenz Peña "fue una de las más débiles que se recuerdan fundamentalmente por dos cuestiones básicas: la falta de apoyo político y el modo de gestión" (Serrafero, 1999a, p. 160). Lo primero se debió a "la carencia de un partido propio y fuerte que le sirviera de apoyo" (p. 161). Mientras que lo segundo, consistió en "el sistema de acuerdos permanentes de gabinete (...), en virtud del cual los asuntos se resolvían por la opinión de la mayoría de los ministros" (1999a, p. 161). El gabinete "se encontraba a cargo de una suerte de primer ministro que llevaba la política del gobierno" (p. 161) (el ministro del Interior o el de Guerra y Marina), mientras que el presidente “aparecía como una figura más distante” (p. 161).

Finalmente, "las convulsiones en las provincias y su política de intervenciones coadyuvaron a que los partidos que los sostenían le retiraran su apoyo" (Serrafero, 1999a, p. 161), al tiempo que provocaron sucesivos reemplazos de ministros, especialmente en la cartera del Interior (Serrafero, 1999a, p. 162). A mediados de 1893 se desató "un levantamiento de origen cívico-autonomista o radical en varias provincias", en San Luis, Santa Fe, Buenos Aires. En pocos meses se produjeron cerca de 20 renuncias ministeriales. En vistas al triunfo de las revoluciones provinciales, Aristóbulo del Valle renuncia "ante maniobras de Carlos Pellegrini que concluyeron en un Congreso contrario al ministro de Guerra" (p. 161). En Interior asume Manuel Quintana, quien logra poner fin a los levantamientos revolucionarios "a través de intervenciones federales y medidas de excepción”, pero luego dimite como consecuencia de su desgaste político. El golpe final vino con la 
renuncia de algunos miembros del gabinete por negarse a incluir en el temario de sesiones del Congreso de 1894 un proyecto de ley de amnistía a los revolucionarios del 93 (p. 164).

\section{José Evaristo Uriburu (1895-1898)}

José Evaristo Uriburu se desempeñó como presidente durante el periodo 1895-1898. En esos años tomó juramento a 10 ministros. Uno de ellos continuó su función como ministro de Relaciones Exteriores, volviendo a jurar nuevamente en el cargo bajo la presidencia de Uriburu. Este departamento fue el único que no tuvo cambios durante su gobierno. En el departamento del Interior ejercieron dos ministros, al igual que en Justicia, Culto e Instrucción Pública y en Hacienda. Por último, el ministerio de Guerra y Marina fue el que tuvo más cambios de dirigentes: tres funcionarios estuvieron al frente de esta cartera.

Tabla 8

Ministros durante la presidencia de José Evaristo Uriburu (1895-1898)

\begin{tabular}{lll}
\hline \multicolumn{1}{c}{$\begin{array}{c}\text { Presidencia de } \\
\text { José Evaristo Uriburu }\end{array}$} & \multicolumn{1}{c}{ Ministro } & \multicolumn{1}{c}{ Período } \\
\hline Del Interior & Benjamín Zorrilla & $23 / 01 / 1895$ a 22/07/1896 \\
\cline { 2 - 3 } & Norberto Quirno Costa & $22 / 07 / 1896$ a 13/10/1898 \\
\hline Relaciones Exteriores & Amancio Alcorta & $23 / 01 / 1895$ a 13/10/1898 \\
\hline Justicia, Culto e & Antonio Bermejo & $23 / 01 / 1895$ a 24/07/1897 \\
\cline { 2 - 3 } Instrucción Pública & Luís Belaustegui & $24 / 07 / 1897$ a $13 / 10 / 1898$ \\
\hline Guerra y Marina & Eudoro Balsa & $23 / 01 / 1895$ a 31/08/1895 \\
\cline { 2 - 3 } & Guillermo Villanueva & $31 / 08 / 1895$ a 20/05/1897 \\
\cline { 2 - 3 } & Nicolás Levalle & $20 / 05 / 1897$ a $13 / 10 / 1898$ \\
\hline \multirow{2}{*}{ Hacienda } & Juan José Romero & $23 / 01 / 1895$ a 22/01/1897 \\
\cline { 2 - 3 } & Wenceslao Escalante & $22 / 01 / 1897$ a 13/10/1898 \\
\hline
\end{tabular}

Fuente: elaboración propia en base a los Libros de Actas de Juramentos de los Miembros del Gobierno de la Nación Argentina.

Durante sus casi cuatro años de mandato, Uriburu, vicepresidente de Luis Saénz Peña y sucesor del mismo tras su renuncia, tuvo 10 gestiones ministeriales. Su IEG fue de 0.54, lo que muestra una estabilidad que se acerca a los valores alcanzados antes de la presidencia de Juárez Celman. Probablemente, esta estabilidad y su "más tranquila admi- 
nistración" pueden explicarse tanto por sus capacidades políticas y su "férrea actitud" (que contrastaban con "la debilidad y el estilo de Sáenz Peña"), como por el hecho de que "contó con el sostén de los notables del régimen" (Serrafero, 1999a, pp. 164-165). Ciertamente, una vez en el poder Uriburu "nombró un nuevo ministerio que reflejaba las fuerzas del 'acuerdo"” con “los hombres clave del régimen” (pp. 164-165).

\section{Sobre la estabilidad de los gabinetes}

Tal como podremos observar más abajo en la tabla 9, en este artículo presentamos el índice de gestión ministerial de ocho gobernantes comprendidos en el periodo 1862-1898: Bartolomé Mitre, Domingo Faustino Sarmiento, Nicolás Avellaneda, Julio Argentino Roca, Miguel Juárez Celman, Carlos Pellegrini, Luis Sáenz Peña y José Evaristo Uriburu. Cabe recordar que durante este periodo tanto la cantidad como las ramas de los ministerios estaban estipuladas por la Constitución, de este modo, la restricción legal era de cinco, número que se corresponde con la cantidad fija de ministerios.

Entre estos ocho gobiernos analizados, el que presenta mayor inestabilidad en el gabinete, según el IEG es, por lejos, la presidencia de Luis Sáenz Peña (2.37). Luego, le siguen, aunque con distancia, Carlos Pellegrini (0.91), Miguel Juárez Celman (0.89) y Nicolás Avellaneda (0.73). De estos cuatro gobiernos, solo el de Luis Saénz Peña tiene un IEG superior a 1, con un valor de 2.37. Los tres restantes están por debajo de 1; esto demuestra gran estabilidad de los gabinetes ministeriales durante este periodo. En tanto, los gobiernos con menor inestabilidad según el mismo índice son las presidencias de Domingo Faustino Sarmiento (0.37), Bartolomé Mitre (0.40), Julio Argentino Roca (0.43) y José Evaristo Uriburu (0.54).

El IEG revela que en el primer periodo analizado, el gabinete con mayor inestabilidad es el correspondiente al gobierno de Luis Sáenz Peña entre los años 1892-1895 con un valor de inestabilidad de 2.37. Efectivamente, este presidente designó un total de 27 ministros en cinco carteras en sus breves 2.28 años de mandato. El gobierno de Sáenz Peña es el caso más paradigmático en este periodo si comparamos los índices de los diferentes gobiernos. El segundo gabinete más inestable, aunque bastante menos que el primero, es el correspondiente al gobierno de Carlos Pellegrini, con un valor de 0.91. Pe- 
llegrini tuvo un total de 10 ministros durante sus 2.3 años al mando del ejecutivo nacional. Si bien la duración del mandato de ambos presidentes es muy similar, la cantidad de ministros que designó Pellegrini equivale aproximadamente a un tercio de los nombrados por Sáenz Peña.

Tabla 9

Índice de Estabilidad de Gabinete por presidencia (1862-1898)

\begin{tabular}{|c|c|c|c|c|c|c|}
\hline Presidente & Período & $\begin{array}{l}\text { Total de } \\
\text { ministros }\end{array}$ & $\begin{array}{c}\text { Cantidad de } \\
\text { ministerios } \\
\text {-Restricción } \\
\text { legal }\end{array}$ & $\mathrm{Y}=\mathrm{X} / \mathrm{RL}$ & $\begin{array}{l}\text { Cantidad } \\
\text { de años del } \\
\text { presidente } \\
(\mathrm{T})\end{array}$ & $\begin{array}{c}\text { Índice de } \\
\text { estabilidad } \\
\text { del gabinete } \\
\text { (IEG =Y } \\
\text { / T) }\end{array}$ \\
\hline $\begin{array}{l}\text { Bartolomé } \\
\text { Mitre }\end{array}$ & $1862-1868$ & 12 & 5 & 2.4 & 6.0 & 0.40 \\
\hline $\begin{array}{l}\text { Domingo } \\
\text { Sarmiento }\end{array}$ & $1868-1874$ & 11 & 5 & 2.2 & 6.0 & 0.37 \\
\hline $\begin{array}{l}\text { Nicolás } \\
\text { Avellaneda }\end{array}$ & 1874-1880 & 22 & 5 & 4.4 & 6.0 & 0.73 \\
\hline $\begin{array}{l}\text { Julio } \\
\text { Argentino } \\
\text { Roca }\end{array}$ & 1880-1886 & 13 & 5 & 2.6 & 6.0 & 0.43 \\
\hline $\begin{array}{l}\text { Miguel } \\
\text { Juárez } \\
\text { Celman }\end{array}$ & $1886-1890$ & 17 & 5 & 3.4 & 3.8 & 0.89 \\
\hline $\begin{array}{l}\text { Carlos } \\
\text { Pellegrini }\end{array}$ & 1890-1892 & 10 & 5 & 2.0 & 2.2 & 0.91 \\
\hline $\begin{array}{l}\text { Luís Sáenz } \\
\text { Peña }\end{array}$ & 1892-1895 & 27 & 5 & 5.4 & 2.3 & 2.37 \\
\hline $\begin{array}{l}\text { José Evaristo } \\
\text { Uriburu }\end{array}$ & 1895- 1898 & 10 & 5 & 2.0 & 3.7 & 0.54 \\
\hline
\end{tabular}

\section{Discusión y conclusiones}

En el presente artículo nos concentramos, en primer lugar, en describir detalladamente la composición de los gabinetes de los titulares del ejecutivo nacional comprendidos en el periodo 1862 a 1898 . Elegimos focalizarnos en este recorte temporal debido a que durante este tramo la cantidad de departamentos de Estado se encontraba fijada por la Constitución nacional. En ella se establecía la existencia de cinco departamentos de Estado, a saber: del Interior, Relaciones Exteriores, Justicia, Culto e Instrucción Pública, Hacienda, y Guerra y Marina. El periodo analizado comprende los gobiernos nacionales de Bartolomé Mitre, Domingo Faustino Sarmiento, Nicolás Avellaneda, Julio Argen- 
tino Roca, Miguel Juárez Celman, Carlos Pellegrini, Luis Sáenz Peña y José Evaristo Uriburu.

Segundo, y como aporte más original de este trabajo, nos ocupamos de construir y aplicar un instrumento que nos permitiera medir el grado de estabilidad o inestabilidad del gabinete de cada presidente, el Índice de Estabilidad de Gabinete, así como de ensayar algunas hipótesis explicativas de los comportamientos observados, siempre tomando en cuenta el contexto histórico en el que se desenvolvían tales gobiernos y sus ministerios.

En términos absolutos, contando solo el número total de ministros designados por cada presidente, las presidencias de Carlos Pellegrini y de José Evaristo Uriburu fueron las que registraron la menor cantidad de cambios en su equipo de gobierno: ambos tuvieron solo 10 ministros cada uno durante la totalidad de sus mandatos, es decir, a razón de dos ministros por cartera, mientras que en el gobierno de Nicolás Avellaneda y, en mayor medida, en el de Luis Sáenz Peña, los cambios de gabinete se sucedieron de forma más frecuente (sumando 22 y 27 ministros, respectivamente).

Sin embargo, en este artículo advertimos la importancia de considerar tanto el tiempo de duración en el gobierno de cada presidente como el contexto político, económico y social en el que comandaron el ejecutivo nacional, variables que, sin duda, impactan de lleno en la estabilidad o inestabilidad verificada en la composición de los respectivos gabinetes.

Si incorporamos, como hicimos en nuestro IEG, la duración relativa de cada gobierno, el panorama cambia radicalmente. La presidencia de Carlos Pellegrini (0.91) pasa a ser la segunda más inestable en la conformación de su gabinete (bastante por detrás de la de Luis Sáenz Peña), mientras que la de Domingo Faustino Sarmiento (0.37) se vuelve la más estable de todas.

Cabe, no obstante, reconocer que los presidentes que asumieron su gestión con un periodo en marcha, esto es, con la misión de completar el mandato de un gobernante que dejó el cargo en forma anticipada, no tienen iguales chances de salir bien calificados bajo este índice que otro que inició un mandato nuevo con seis años por delante. En el primer caso, el presidente reemplazante ya desde el comienzo no podrá 
aspirar a alcanzar el valor mínimo calculado al inicio de este artículo (0.166), que coincide con la máxima estabilidad de gabinete posible para un periodo de seis años. Es decir, por más que no cambie ningún ministro durante toda su gestión, al ser su tiempo en el gobierno menor a seis años, el resultado de su índice será mayor. De todos modos, nos parece válido sostener la formulación de nuestra herramienta tal y como ha sido presentada en esta oportunidad, ya que,en términos objetivos, la estabilidad de un gabinete es mayor cuanto más tiempo dura un ministro bajo el mismo presidente, independientemente de si la duración real de tal presidente en el cargo coincide o no con la máxima posible en términos constitucionales, e independientemente también de los motivos de la salida anticipada en caso de haberla.

Llegados a este punto, estamos en condiciones de afirmar que el objetivo de medir el grado de estabilidad o inestabilidad de los gabinetes por cada presidencia ha sido cumplido, en tanto logramos presentar las primeras mediciones de nuestra herramienta de análisis. Según el IEG, en este primer periodo el gabinete de Luis Sáenz Peña fue el más inestable, mientras que el de Domingo Faustino Sarmiento exhibió la mayor estabilidad. Por otro lado, es posible agregar que el Ministerio de Hacienda fue el que mayor cantidad de cambios de conducción sufrió durante este periodo, mientras que el Ministerio de Guerra y Marina tuvo la mayor estabilidad en su conducción.

Ahora bien, presentados los primeros resultados de nuestro índice, la explicación de los diversos grados de estabilidad/inestabilidad de los gabinetes debe buscarse en razones que hacen al contexto social, político y económico del país, lo que demanda una lectura histórica del periodo.

A modo de síntesis, podemos subdividir estos años en dos tramos: 1862-1886 y 1886-1898. En lo que hace al primer tramo, se observa que los gobiernos de Bartolomé Mitre, Domingo Faustino Sarmiento, Nicolás Avellaneda y Julio Argentino Roca completaron la duración fija del mandato establecido por la Constitución Nacional de 1853 (seis años). Aquí, el gobierno de Nicolás Avellaneda demostró una muy alta inestabilidad en el gabinete, ya que este presidente nombró 22 ministros durante su mandato (a razón de 4.4 ministros por cartera). Esta cantidad es superior a la del número de ministros de Mitre, de Sarmiento y de Roca (considerados individualmente). Tales cambios en el gabine- 
te estuvieron asociados con un intento de conciliación del presidente Avellaneda con la facción de Mitre tras haberlo derrotado en las elecciones presidenciales correspondientes. Ciertamente, ante la tensión social emergente entre las facciones del partido, Avellaneda convocó a Saturnino Laspiur, a José María Gutiérrez y a Rufino de Elizalde a sumarse a su gabinete y sellar así una alianza con el mitrismo.

Por otro lado, los gobiernos posteriores a 1886 estuvieron atravesados por una evidente inestabilidad en la duración de los gobiernos, ya que ninguno pudo completar la totalidad del mandato. Miguel Juárez Celman debió renunciar en virtud de las consecuencias políticas que desató la Revolución del Parque, por lo que su gobierno duró aproximadamente cuatro años (dos tercios del total). Carlos Pellegrini asumió la presidencia tras la renuncia de Juárez Celman y ocupó el cargo hasta cumplido el mandato de este en 1892. Luis Sáenz Peña asumió en 1892, pero debió renunciar en 1895 por la pérdida de legitimidad de su gobierno, de forma que su vicepresidente, José Evaristo Uriburu, ocupó su lugar hasta completar el mandato en 1898.

Tras lo anterior es posible sostener que el periodo de inestabilidad política iniciado en 1890, con la insurrección comandada por Além, tuvo consecuencias claras en el accionar de los gobiernos y en la composición de sus gabinetes. Con seguridad, el caso que mejor ejemplifica esta relación es el gobierno de Luis Sáenz Peña, el que en escasos tres años de gestión nombró 27 ministros entre los cinco ministerios.

Por último, cabe recordar que, más allá de la propuesta y aplicación de dicho índice, en este artículo nos ocupamos con igual esmero de ofrecer una primera aproximación descriptiva de la composición ministerial argentina desde los inicios del Estado, tomando como fuente los Libros de Actas de Juramentos de los Miembros del Gobierno de la Nación Argentina. Dicho esfuerzo permitió reunir y sistematizar una gran cantidad de información que hasta el momento no se encontraba disponible públicamente y que aún no ha sido explorada en profundidad.

En tal sentido, consideramos que este estudio detallado ofrece herramientas confiables para analizar el periodo y para avanzar en investigaciones específicas respecto de otras cuestiones centrales, tales como el grado de estabilidad o inestabilidad de los gabinetes por cartera en cada presidencia, la existencia de patrones de conducta si- 
milares o diferentes en cuanto a la composición y permanencia de los ministros y los ministerios entre gobiernos democráticos y gobiernos de facto, el nivel de rotación de una misma persona entre las distintas carteras y entre diversas presidencias, y muchas otras hasta el momento poco o nada exploradas.

\section{Referencias}

Abal Medina, J. M. (2019). Gobiernos y gobernantes de la República Argentina. Revista POSTData, 24(1), 11-34.

Aelo, O. H. (2006). Formación y crisis de una elite dirigente en el peronismo bonaerense, 1946-1951. En. J. C. Melón Pirro y N. Quiroga (Eds.), El peronismo bonaerense: Partido y prácticas políticas, 1946-1955. (pp. 15-42). Mar del Plata: Suárez.

Amorim Neto, O. (2002). Presidential policy-making strategies and cabinet formation in Latin America's presidential democracies, 1946-1995. Trabajo presentado en la Conferencia El Gobierno Dividido en México: Riesgos y Oportunidades. México D.F.: Congreso de México.

Amorim Neto, O. (2006). The presidential calculus. Executive policy making and cabinet formation in the Americas. Comparative Political Studies, 39(4), 415-440.

Araujo Filho, V. (2016). Presidentes fortes e presidência fraca: A expansão do poder executivo e a organização da presidência da república (1930-1989). Curitiba: Appris.

Arismendi, A. (1998). El jefe de gabinete en la reforma constitucional argentina. ¿Un ejemplo a seguir? Revista de la Facultad de Ciencias Jurídicas y Políticas, (107), 46-60. Recuperado de http://www.ulpiano.org.ve/revistas/bases/artic/texto/ RDUCV/107/rucv_1998_107_45-60.pdf

Bonaudo, M. \& Sonzogni, E. (1999). Los grupos dominantes entre la legitimidad y el control. En M. Bonaudo (Dir.), Liberalismo, estado y orden burgués (1852-1880) (Vol. 4, Nueva historia argentina, pp. 27-96). Buenos Aires: Sudamericana.

Botana, N. R. (1977). El orden conservador: La política argentina entre 1880 y 1916. Buenos Aires: Sudamericana.

Camerlo, M. (2013). Gabinetes de partido único y democracias presidenciales. Indagaciones a partir del caso argentino. América Latina Hoy, (64), 119-142. 
Camerlo, M. \& Coutinho, M. E. (2019). Ministros y afiliación partidaria. Propuesta metodológica aplicada al caso argentino. América Latina Hoy, (81), 99-118.

Camerlo, M. \& Martínez-Gallardo, C. (Eds.) (2018). Government formation and minister turnover in presidential cabinets: Comparative analysis in the Americas. Nueva York: Routledge.

Campos Ríos, M. (2012). La organización del gabinete en Argentina: Un estudio de caso perspectiva comparada, de Alfonsín a Kirchner. (Tesis de maestría) Departamento de Ciencias Sociales, Universidad de San Andrés, Buenos Aires, Argentina. Recuperado de http://hdl.handle.net/10908/926.

Campos Ríos, M. (2019). El gabinete argentino en democracia: De Alfonsín a Fernández. Estado abierto, 4(1), 103-162.

Carreras, M. (2013). Presidentes outsiders y ministros neófitos: Un análisis a través del ejemplo de Fujimori. América Latina Hoy, (64), 95-118.

Chasquetti, D., Buquet, D. \& Cardarello, A. (2013). La designación de gabinetes en Uruguay: Estrategia legislativa, jerarquía de los ministerios y afiliación partidaria de los ministros. América Latina Hoy, (64), 15-40. Recuperado de http://www.redalyc. org/articulo.oa?id=30827842002

Congreso General Constituyente (2015). Constitución para la Confederación Argentina. En N. Monti (Coord.), Constituciones argentinas. Compilación histórica y análisis doctrinario. (pp. 135-156). Buenos Aires: Ministerio de Justicia y Derechos Humanos, Infojus.

Convención Nacional (2015). Texto de la reforma constitucional de 1898. En N. Monti (Coord.), Constituciones argentinas. Compilación histórica y análisis doctrinario. (pp. 179-180). Buenos Aires: Ministerio de Justicia y Derechos Humanos, Infojus.

Coutinho, M. E. (2008). Un análisis de la organización de la presidencia en la Argentina. Colección, (18-19). 17-47. Recuperado de http://erevistas.uca.edu.ar/index.php/COLEC/article/ view/806/774

Coutinho, M. E. (2019). De la periferia al centro. El derrotero institucional de la jefatura de gabinete de ministros en la presidencia argentina. GIGAPP Estudios Working Papers, 5(98-110), 477-492. Recuperado de http://www.gigapp.org/ewp/index. php/GIGAPP-EWP/article/view/119. 
Cruz Barbosa, S. (noviembre, 2010). Evaluando las instituciones políticas de gobierno de coordinación nacional en Argentina: el rol del jefe de gabinete de ministros en la Argentina pos reforma. Un análisis desde la Ciencia Política, instituciones políticas. Trabajo presentado en el XXIII Congreso del Centro Latinoamericano de Administración para el Desarrollo sobre Reforma del Estado y Modernización de la Administración Pública, Caracas, Venezuela. Recuperado de http://siare.clad.org/ fulltext/0065402.pdf

Dávila, M., Olivares Lavados, A. \& Avendaño, O. (2013). Los gabinetes de la Concertación en Chile (1990-2010). América Latina Hoy, (64), 67-94.

Donatello, L. M. \& Levita, G. (2017). ¿Renovación de las élites o renovación de las élites políticas? Los diputados outsiders en los países del MERCOSUR. Revista de Investigaciones Políticas y Sociológicas, 16(2), 45-64.

Ferrari, M. (2012). Acerca del abordaje sociográfico de los elencos políticos, sus prácticas y autorrepresentaciones. Algunas reflexiones. Revista PolHis, 5(9), 241-250.

Gandía de, E. (1979). Julio Argentino Roca. Anales de la Academia Nacional de Ciencias Morales y Políticas, 8, 27-54.

Gené, M. (septiembre, 2007). Cambios en la forma de construir poder político desde el Estado. Una mirada desde los ministerios de economía e interior. Trabajo presentado en IV Jornadas de Jóvenes Investigadores, Instituto de Investigaciones Gino Germani, Buenos Aires, Argentina. Recuperado de https:// www.aacademica.org/000-024/239.pdf

Giorgi, G. (2014a). Los factores "extrapolíticos" de la carrera política: Una aproximación a las sociabilidades de los ministros de la nación en la Argentina (1854-2011). Política. Revista de Ciencia Política, 52(2), 241-273.

Giorgi, G. (2014b). Ministros y ministerios de la nación argentina: Un aporte prosopográfico para el estudio del gabinete nacional (1854-2011). Apuntes. Revista de Ciencias Sociales, 41(74), 103-139.

Halperin Donghi, T. (1980). Proyecto y construcción de una nación (Argentina 1846-1880). Caracas: Biblioteca Ayacucho.

Heredia, M. (2017). Sociología de las elites. Épocas. Revista de Ciencias Sociales y Crítica Cultural, (4). Recuperado de http:// 
revistaepocas.com.ar/mariana-heredia-sociologia-de-laselites/.

Heredia, M., Gené, M. \& Perelmiter, L. (2012). Hacia una socio-historia del gabinete nacional. Revista PolHis, 5(9), 284-290.

Inácio, M. (2013). Escogiendo ministros y formando políticos: Los partidos en gabinetes multipartidistas. América Latina Hoy, (64), 41-66.

Martínez-Gallardo, C. (2012). Out of the cabinet: What drives defections from the government in presidential systems? Comparative Political Studies, 45(1), 62-90.

O'Donnell, G. (1977). Apuntes para una teoría del Estado. (Documento No 9) Buenos Aires: Centro de Estudios de Estado y Sociedad (CEDES) y Consejo Latinoamericano de Ciencias Sociales. Recuperado de http://www.top.org.ar/ecgp/ FullText/000000/O\%20DONNELL\%20Guillermo\%20-\%20 Apuntes\%20para\%20una\%20teoria\%20del\%20estado.pdf

Ollier, M. M. \& Palumbo, P. (2016). ¿Caso testigo o caso único? Patrones de la formación de gabinete en el presidencialismo argentino (1983-2015). Colombia Internacional, (87), 53-80.

Olivares, N. E. (2018). El momento Mitre. Retórica y aporías de una república liberal nacionalista rioplatense. Revista de Historia, (19), 133-166.

Oszlak, O. (1982). Reflexiones sobre la formación del Estado y la construcción de la sociedad argentina. Desarrollo Económico. Revista de Ciencias Sociales, XXI, 1-18. Recuperado de http:// www.unl.edu.ar/ingreso/cursos/sociales/wp-content/ uploads/sites/3/2016/10/Reflexiones-sobre-la-form-delE_Oszlak.pdf

Oszlak, O. (2004). La formación del Estado argentino. Orden, progreso y organización nacional. Buenos Aires: Ariel Historia.

Rojkind, I. (2012). "La revolución esta vencida, pero el gobierno está muerto". Crisis política, discurso periodístico y demostraciones callejeras en Buenos Aires, 1890. Anuario de Estudios Americanos, 69(2), 507-532.

Sábato, H. (2005). Pueblo y política. La construcción de la república. Buenos Aires: Capital Intelectual.

Sábato, H. (2012). Historia de la Argentina, 1852-1890. Buenos Aires: Siglo XXI. 
Sáenz Quesada, M. (2001). La Argentina. Historia del país y de su gente. Buenos Aires: Sudamericana.

Sambuccetti de, S. I. R. (1971). Del "Boom" a la crisis: Las presidencias de Juárez Celman y Carlos Pellegrini. Revista de Historia de América, (71), 67-117.

Serrafero, M. D. (1994). Una reflexión a propósito del jefe de gabinete y la censura parlamentaria. El Derecho, (8580), 13 de septiembre, 6-7.

Serrafero, M. D. (1999a). El poder y su sombra. Los vicepresidentes. Buenos Aires: Editoral de Belgrano.

Serrafero, M. D. (1999b). Presidencialismo argentino: ¿Atenuado o reforzado? Araucaria. Revista Iberoamericana de Filosofía, Política, Humanidades y Relaciones Internacionales, 1(2), 121154. Recuperado de https://revistascientificas.us.es/index. $\mathrm{php} /$ araucaria/article/view/876

Serrafero, M. D. (2003). La jefatura de gabinete y las crisis políticas: El caso De la Rúa. Revista SAAP, 1(2), 247-272. Recuperado de https://revista.saap.org.ar/contenido/revista-saap-v1-n2/ serrafero.pdf

Serrafero, M. D. (2011). El área de estudios presidenciales. Anales de la Academia Nacional de Ciencias Morales y Políticas, 38, 5-42. Recuperado de https://www.ancmyp.org.ar/user/files/13Serrafero-2011.pdf

Serrafero, M. D. (2014). Flexibilización del presidencialismo en América Latina: ¿Un fenómeno nuevo? Revista de Estudios Políticos, (163), 67-99. Recuperado de https://recyt.fecyt.es/ index.php/RevEsPol/article/view/36285

Valadés, D. (2003). El gobierno de gabinete. México, D. F.: Instituto de Investigaciones Jurídicas, UNAM.

Vedoya, J. C. (1979). La magra cosecha, 1868-1874. Buenos Aires: Ediciones La Bastilla. 